\title{
Nausea and vomiting after gynaecological laparoscopy depends upon the phase of the menstrual cycle
}

Postoperative nausea and vomiting were compared in 68 women with regular menstrual periods undergoing gynaecological laparoscopy. The patients were divided into four groups on the basis of the phase of the menstrual cycle as follows: premenstrum-menstrum (pre + menstrum) (Pd 25-6), early follicular phase (Pd 8-12), ovulatory phase (Pd 13-15) and luteal phase (Pd20-24). The overall incidence of nausea and vomiting was $46 \%$. Statistically significant differences in the incidence of nausea and retching were found among the groups by regression analysis. The incidence of nausea and vomiting was highest in women undergoing laparoscopy during the luteal phase (77\%), which was greater than during the follicular phase (32\%) or during pre+menstruation (18\%). The need for antiemetic was highest in women undergoing laparoscopy during the luteal phase $(69 \%)$ and this was different from the follicular $(18 \%, P$ $<0,01)$ and pre+menstrum $(19 \%, P<0,01)$ phases. It is concluded that the highest incidence of postoperative nausea and vomiting after gynaecological laparoscopy occurs during the luteal phase.

Les nausées et les vomissements postopératoires ont été comparés chez 68 femmes ayant des menstruations régulières et subissant une laparoscopie gynécologique. Les patientes furent divisées en quatre groupes en se basant sur la phase de leur cycle menstruel comme suit: prémenstruation-menstruation (pré+ menstruations) (Pd 25-6), la phase folliculaire précoce

\section{Key words}

ANAESTHESIA: gynaecological;

HORMONES: oestradiol;

VOMITING: incidence, nausea.

From the Department of Anaesthesia, Women's Clinics,

Helsinki University Central Hospital, Helsinki, Finland.

Address reprint requests to: Dr. Pekka Honkavaara, Department of Anaesthesia, Women's Clinics, Helsinki University Central Hospital, Haartmaninkatu 2, SF-00290, Helsinki 29, Finland.

Accepted for publication 28th May, 1991.
Pekka Honkavaara MD, Ann-Mari Lehtinen MD PhD, Jaromir Hovorka MD, Kari Korttila MD PhD
(Pd 8-12), la phase ovulatoire (Pd 13-15) et la phase lutéale (Pd 20-24). L'incidence globale de nausées et de vomissements était de $46 \%$. Une différence statistiquement significative fut trouvée entre les groupes par analyse de régression. L'incidence de nausées et de vomissements était plus grande chez les femmes subissant la laparoscopie durant la phase lutéale (77\%) et cette incidence fut plus grande que lors de la phase folliculaire $(32 \%)$ ou durant la phase de prét menstruation (18\%). Le besoin d'antiémétique était plus grand chez les femmes subissant la laparoscopie durant la phase lutéale (69\%) et ceci était différent du groupe en phase folliculaire $(18 \%, P<$ $0,01)$ et du groupe pré-menstruel (19\%, $P<0,01)$. On conclut que la plus haute incidence de nausées et de vomissements après laparoscopie est survenue lors de la phase lutéale.

The incidence of nausea and vomiting after general anaesthesia for gynaecological laparoscopy may be as high as $50 \% .{ }^{1}$ Recently, it has been suggested that the menstrual cycle may affect the incidence of postoperative nausea and vomiting with the highest incidence occurring during menstruation. ${ }^{2}$ Therefore, we decided to investigate the relationship between menstrual cycle and nausea and vomiting in fertile women undergoing gynaecological laparoscopy.

\section{Methods}

We reevaluated 150 (ASA physical status I and II) patients, each of whom had given informed consent for a previous study ${ }^{3}$ which was designed to evaluate postoperative nausea and vomiting after gynaecological laparoscopy with one of three anaesthetic techniques. This study was chosen because it did not show any statistically significant differences in the incidence or severity of nausea and vomiting among the anaesthesia groups. Patients from the previous study were included if they did not meet with the following exclusion criteria:

- patients with incomplete medical records

- patients receiving hormones or drugs affecting ovulatory cycle 
- patients with menstrual cycle abnormalities

- patients with pregnancy or who were breast feeding or less than two months from termination of pregnancy

- patients with abnormal uterine or ovarian status

- climacteric patients

The exact date of menstruation was obtained from the patient's records. After careful scrutinizing all patient documents and records 89 women with histories of regular menstrual periods were divided into the following four groups on the basis of the phase of the menstrual cycle:

Follicular phase Pd 8-12 $(n=22)$

Ovulation $\quad \mathrm{Pd} 13-15(n=22)$

Luteal phase $\quad \operatorname{Pd} 20-24(n=13)$

Pre + menstrum Pd 25-6 $(n=11)$

The definition of the days of the menstrual phases are based on the physiological and endocrinological changes in normal menstrual cycles. Therefore there are gaps $\mathrm{Pd} 7$ and Pd 16-19, and only 68 women remained in the study.

\section{Anaesthesia}

All patients received premedication with oxycodone 0.13 $\mathrm{mg} \cdot \mathrm{kg}^{-1}$ im $40-60 \mathrm{~min}$ before anaesthesia. After insertion of an iv cannula and starting an infusion of Ringer's lactate solution, $0.2 \mathrm{mg}$ glycopyrrolate, $0.8 \mathrm{mg}$ vecuronium, and $0.1 \mathrm{mg}$ fentanyl were administered. Three minutes later anaesthesia was induced with $4 \mathrm{mg} \cdot \mathrm{kg}^{-1}$ thiopentone. Before tracheal intubation, the lungs were ventilated by mask and intubation was facilitated with 1.5 $\mathrm{mg} \cdot \mathrm{kg}^{-1}$ succinylcholine. Anaesthesia was maintained with inhalational agents (isoflurane $1 \%$ in oxygen $30 \%$ and nitrous oxide $70 \%$, or isoflurane $1.5 \%$ in air-oxygen $30 \%$, or enflurane $1.2 \%$ in oxygen $30 \%$ and nitrous oxide $70 \%$ ). Vecuronium was used to maintain neuromuscular blockade at $20-25 \%$ of the patient's normal muscle power as assessed using a neurostimulator.

After the initial vaporiser setting the concentration was adjusted to give the lowest concentration of inhalational agent compatible with the clinical need. The concentration was altered if the systolic blood pressure or heart rate changed more than 25\% from the baseline. End-tidal $\mathrm{CO}_{2}$ was measured continuously with a capnometer and maintained at $5.0-5.5 \%$. At the end of anaesthesia, glycopyrrolate $0.4 \mathrm{mg}$ and neostigmine $2.0 \mathrm{mg}$ were given $i v$. Oxycodone chloride was used to relieve postoperative pain. It was administered $i v$ in the recovery room in 3-4 $\mathrm{mg}$ increments and thereafter $\mathrm{im}$ in the ward at a dose of $0.13 \mathrm{mg} \cdot \mathrm{kg}^{-1}$.

\section{Assessment of emesis}

The incidence of nausea and vomiting was determined at four different intervals during the first $24 \mathrm{hr}$ after the operation. At the end of each interval a trained nurse, who was unaware of the goal of the study, registered whether nausea, retching or vomiting had occurred. The results were scored, in a manner similar to that of Bellville et al.: ${ }^{4}$ none, nausea, retching, vomiting. Droperidol 1.25 $\mathrm{mg}$ was administered once during each period for prolonged nausea or vomiting. If a patient experienced more than one symptom, for example both nausea and vomiting, she was listed as having had vomiting. Comparison among the groups were performed for overall nausea, retching and vomiting during 0 to $24 \mathrm{hr}$ after anaesthesia.

\section{Statistical analyses}

An ANOVA and contingency table were used for comparison of the demographic data as appropriate. Chi-square test was used to compare the droperidol given to patients in the four groups. BMDPLR logistic regression analysis (VAX/VMS) was used to determine whether the anaesthetic technique, age, duration of anaesthesia, oxycodone treatment or the phase of menstrual cycle was significant in predicting the individual suffering from nausea, retching or vomiting. The same analysis was used to find out the correlation between phase of menstrual cycle and the need of antiemetic. A $P$-value less than 0.05 was considered statistically significant.

\section{Results}

There were no complaints of awareness during anaesthesia in any anaesthesia group, and all three techniques provided satisfactory anaesthesia with good surgical conditions and patient acceptance.

The patient groups (Table) did not differ with respect to: age, height, weight, duration of anaesthesia, postoperative oxycodone dose, history of alcohol consumption, type of anaesthesia and type of surgery.

The type of anaesthesia, age, weight, duration of anaesthesia and oxycodone postoperatively were not significant predictors for nausea, retching or vomiting.

Nitrous oxide, compared with air and oxygen, did not affect the incidence of nausea and vomiting $(P=0.61$, Chi-square). The three different techniques did not differ in regard of nausea and vomiting $(P=0.63$, Chi-square $)$. Also, the type of surgery was not different $(P=0.79$, Chi-square) among the groups.

The logistic regression analysis showed that the phase of ovulatory cycle was a predictor for nausea $(P<0.01)$ and retching $(P<0.005)$. Women undergoing laparoscopy during the luteal phase experienced nausea and vomiting in $77 \%$ of cases which was more than the women anaesthetized during the follicular $(32 \%)$ or pre + menstrual phases $(18 \%)$. Of the women in ovulatory phase $54 \%$ experienced nausea and vomiting (Figure).

None of the women experienced retching or vomiting in the pre+menstrual group. In these women, the inci- 
TABLE Demographic data of 68 female patients (values are mean \pm SD)

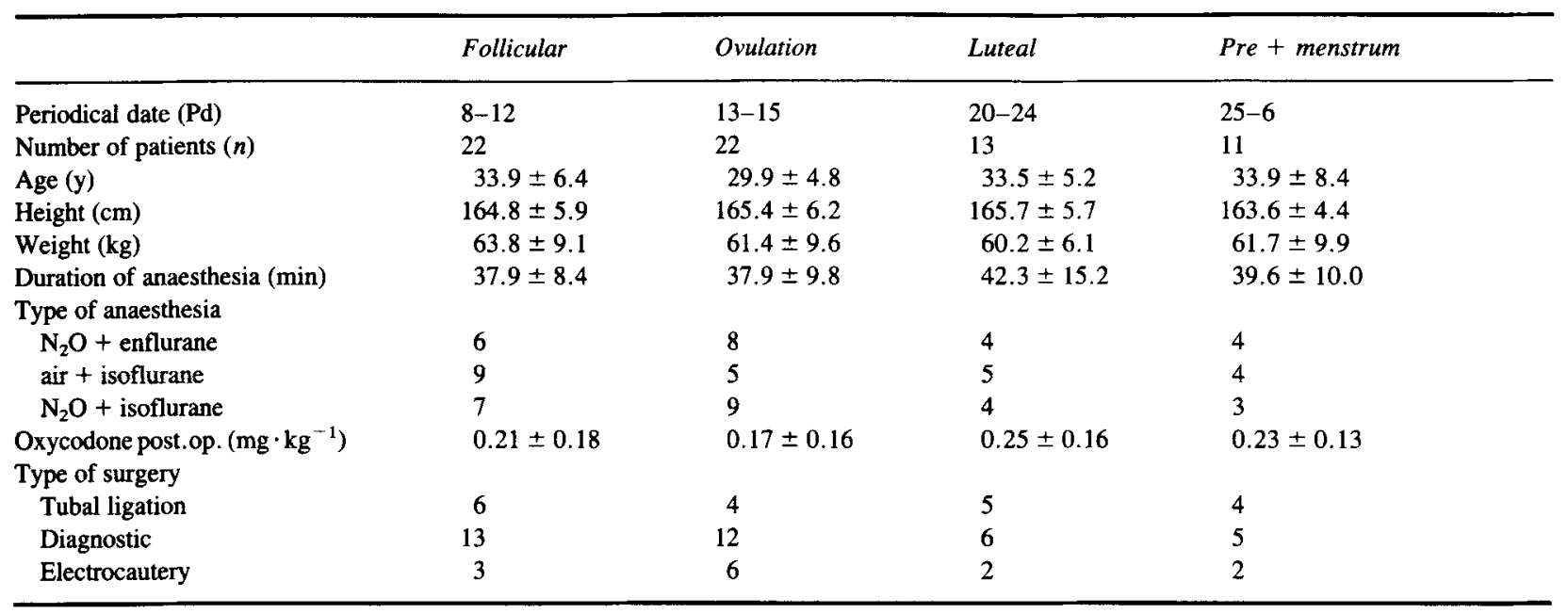

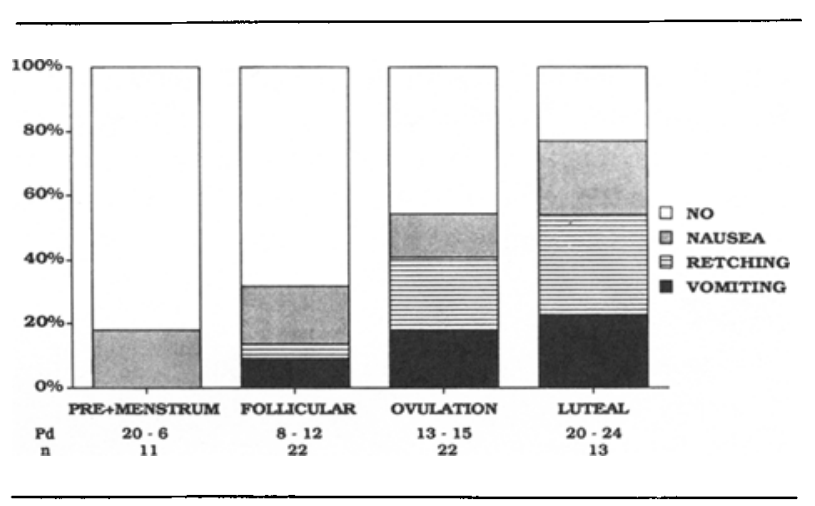

FIGURE Overall incidence of postoperative nausea, retching and vomiting during the $24 \mathrm{hr}$ after gynaecological laparoscopy in different phases of the menstrual cycle. The phase of ovulatory cycle is a predictor for nausea $(P<0.01)$ and for retching $(P<0.005)$. Pd $=$ periodical date, $n=$ number of patients in the group.

dence of retching was different from women anaesthetized in the luteal $(54 \%)$ or the ovulatory phases $(41 \%)$. Retching was also more common in luteal than in the follicular phase (14\%). This study showed no difference in the incidence of vomiting during the first $24 \mathrm{hr}$ postoperatively in relation to the menstrual cycle.

The need for an antiemetic (droperidol) was highest in women undergoing laparoscopy in the luteal phase $(69 \%)$, than in the follicular phase $(18 \%, P<0.01$, Chi-square), or in the pretmenstrum phase $(19 \%, P<$ 0.01 , Chi-square). Logistic regression analysis showed that the phase of ovulatory cycle was a predictor for need of antiemetics $P<0.005$.

\section{Discussion}

In the present study, the menstrual cycle was confirmed by documentation of the history of menstruation. The women undergoing laparoscopies due to infertility had been carefully examined and had normal ovulatory cycles. During gynaecological operations, direct manipulation of ovaries may cause alterations especially in reproductive hormone levels. In the present retrospective study the groups were comparable, since the same manipulative procedures were performed in all patients.

The women studied were undergoing gynaecological laparoscopies during different phases of the menstrual cycle. Nausea and vomiting after laparoscopic ovum retrieval have been shown to be greater in women with high oestrogen levels. ${ }^{5}$ The amount of oestradiol excretion in normal women during different physiological phases of menstrual cycle was taken into consideration in this study when choosing the periodical dates for the four groups. ${ }^{6}$ In the follicular phase (Pd 8-12) Graafs follicles are formed and the plasma gonadotrophin (LH, FSH) levels as well as the ovarian hormone (oestrogen, progesterone) secretion remains on the basal level. Ovulation, the rupture of follicles, is associated with an increase in LH, FSH and oestrogen levels during the 13-15 periodical dates. An increase in progesterone secretion during days 20-24 of menstrual cycle confirms the existence of a corpus luteum, and that ovulation has occurred. In the present study no hormonal measurements were performed. Despite the fact that the study included only women with a history of normal menstrual cycles, the possibility of an anovulatory cycle during the study is not excluded. Although the definition of the periodical dates provided a sound basis to this study, suggesting an association between oestrogen secretion and the incidence of postoperative nausea and vomiting, the correlation between the plasma oestrogen concentrations and postoperative nausea and vomiting needs to be studied separately. 
The specific aetiology of postoperative nausea and vomiting is still obscure. It is known that neurons of the area postrema function in the brain act as the chemoceptive trigger zone for emesis. It has been suggested that a wide variety of transmitters, peptides and hormones may be involved in triggering the emetic reflexes. ${ }^{7}$ Postoperative nausea has been suggested to be more common in women undergoing laparoscopy for ovum retrieval than for other kinds of laparoscopies or surgical procedures. ${ }^{8}$ Women undergoing ovum retrieval for in vitro fertilization have often been treated with hormone stimulation and their preoperative oestrogen levels are high. ${ }^{9}$ It is also known that the most frequent unpleasant symptom following the use of high doses of oestrogen is nausea. ${ }^{10}$

The present study showed that postoperative nausea was more common in women undergoing laparoscopy during the luteal phase than in women operated premenstrually, during the days of menstruation or during the follicular phase. Our results do not agree with studies suggesting that menstruation increases the risk of postoperative emesis. ${ }^{2,11}$ These differences stress the importance of combining measurements of oestradiol and progesterone in further studies.

In conclusion, our study showed that nausea and vomiting was more frequent in women undergoing laparoscopy during the luteal phase of the menstrual cycle than in the pre +menstrum and follicular phases. None of the women who were anaesthetized during menstruation suffered postoperative vomiting. The role of ovarian hormones in the incidence of postoperative nausea and vomiting represent an interesting area for further investigation.

\section{References}

1 Wetchler $B V$, Sung $Y F$, Duncalf $D$, Joslyn $A F$. Ondansetron decreases emetic symptoms following outpatient laparoscopy. Anesthesiology 1990; 73: A36.

2 Lindblad T, Beattie WS, Buckley DN, Forrest JB. Increased incidence of postoperative nausea and vomiting in menstruating women. Can J Anaesth 1989; 36: S78-9.

3 Hovorka J, Korttila K, Erkola O. Nitrous oxide does not increase nausea and vomiting following gynaecological laparoscopy. Can J Anaesth 1989; 36: 145-8.

4 Bellville $J W$, Bross IDJ, Hawland WS. A method for the clinical evaluation of antiemetic agents. Anesthesiology 1959; 20: 753-60.

5 Lindblad T, Forrest JB, Buckley DN, Beattie WS. Anaesthesia decreases a hormone mediated threshold for nausea and vomiting. Anesth Analg 1990; 70: S242.

6 Brown JB, Harrison P, Smith MA, Burger HG. Correlations between the mucus symptoms and the hormonal markers of fertility throughout reproductive life.
Melbourne, Ovulation Method Research and Reference Centre, 1981.

7 Carpenter DO, Briggs DB, Knox AP, Strominger $N$. Excitation of area postrema neurons by transmitters, peptides and cyclic nucleotides. J Neurophysiol 1988; 59: 358-69.

8 Pataky AO, Kitz DS, Andrews RW, Lecky JH. Nausea and vomiting following ambulatory surgery: are all procedures created equal? Anesth Analg 1988; 67: S163.

9 Lehtinen A-M, Laatikainen T, Koskimies AI, Hovorka $J$. Modifying effects of epidural analgesia or general anesthesia on the stress hormone response to laparoscopy for in vitro fertilization. J Vitro Fert Embryo Transfer 1987; 4: 23-9.

10 Murad F, Haynes RC. Estrogens and progestins. In: Goodman and Gilman. The Pharmacological Basis of Therapeutics. 7th ed. New York: Macmillan publishing Company 1985. 